\title{
O FIM DAS FILOSOFIAS DA HISTÓRIA: LIBERDADE E DIALÉTICA
}

Delamar José Volpato Dutra*

SÍNTESE - A Escola de Frankfurt abandona, progressivamente, as teses da filosofia da história, cuja aceitação fornecia uma espécie de fundamento para a teoria critica, na medida em que se podia confiar nos conteúdos emancipatórios da razão, embutidos nos ideais da sociedade burguesa: Tentaremos mostrar o pressuposto obliterado das teses da filosofia da história a partir da dialética do senhor e do escravo de Hegel, e por que, então, tais teses mostraram-se insuficientes. Por fim, buscaremos demonstrar que a figuração teónica do oposto às teses da filosofia da história encontra-se nos Utber den Begriff der Geschichte de Benjamin. Além disso, a recuperação de um tal fundamento obliterado nas teses da filosofia da históna determina, a nosso ver, a consideração moral da teoria crítica habermasiana.

PALAVRAS-CHAVE - Dialética. Liberdade. Hegel. Adomo.
ABSTRACT - The Frankfurt School increasingly gives away the main thesis of the philosophy of history. Their acceptance had provided the foundation for critical theory insofar as it could rely on the emancipatory contents of reason inherent to the ideals of burgeois society. We shall try to uncover the obliterated assumptions of the theses of the philosophy of history using Hegel's dialectic of the servant and the master and to show why they were not sufficient. Finally, we shall seek to demonstrate that the theoretical configuration in opposition to such theses can be found in Benjamin's Uber den Begriff der Geschichte. Furthermore, we believe that the recovery of such a foundation, obliterated in the theses of the philosophy of history, determines the moral consideration of Habermas's critical theory.

KEY WORDS - Dialectic. Freedom. Hegel. Adorno.

"O pensamento dialético é a tentativa de quebrar o caráter coercitivo da lógica com os próprios meios desta última. Mas, na medida em que ele tem que se servir desses meios, ele se arrisca sem cessar a sucumbir, ele próprio, a esse caráter coercitivo: a astúcia da razão poderia impor-se mesmo contra a dialética. ${ }^{11}$

\section{Marx}

A busca de uma explicação científica da história, por Marx, enraíza-se numa tese da filosofia da história. Tais concepções referentes à história implicam, sempre, a existência de um mecanismo cujo funcionamento determina a realização de

* Professor da UFSC (Universidade Federal de Santa Catarina).

ADORNO, Th. Minima moralia. São Paulo: Ática, 1992. p. 132, § 98. 
um fim que pode ser perscrutado de forma racional na história. Assim, já Kant concebia um mecanismo natural, ${ }^{2}$ a sociabilidade insociável, ${ }^{3}$ capaz de civilizar 0 gênero humano. A idéia de um ardil da razão ${ }^{4}$ em Hegel pode ser considerado, também, o meio de que a razão se serve para concretizar-se, apesar dos homens e suas paixões, mas, também, através desses e daquelas. ${ }^{5}$

De fato, Marx afirma:

"na produção social da própria vida, os homens contraem relações determinadas, neces-
sárias e independentes de sua vontade, relações de produção estas que correspondem a
uma etapa determinada de desenvolvimento das suas forças produtivas materiais. A tota-
lidade destas relações de produção forma a estrutura econômica da sociedade, a base
real sobre a qual se levanta uma superestrutura jurídica e política, e à qual correspondem
formas sociais determinadas de consciência. O modo de produção da vida material con-
diciona o processo em geral de vida social, politico e espiritual. Não é a consciência dos
homens que determina o seu ser, mas, ao contrário, é o seu ser social que determina sua
consciência. Em uma certa etapa de seu desenvolvimento, as forças produtivas materiais
da sociedade entram em contradição com as relações de produção existentes ou, o que
nada mais é do que a sua expressão jurídica, com as relações de propriedade dentro das
quais aquelas até então se tinham movido. De formas de desenvolvimento das forças
produtivas, estas relaçōes se transformam em seus grilhöes. Sobrevém então uma época
de revolução social. Com a transformação da base econômica, toda a enorme superes-
trutura se transforma com maior ou menor rapidez."

Pois bem, o axioma básico da teoria marxista da história reside, logo ao início, na proposição que estabelece a correspondência entre as forças produtivas e as relações de produção. A esse axioma deve-se acrescentar o teorema da contradição entre as forças produtivas e as relações de produção, determinando, dessa forma, uma mudança nas relações de produção a cada mudança nas forças produtivas e, consequientemente, uma mudança em toda a superestrutura da sociedade. Cabe destacar que as transformações materiais das condições econômicas de produção "pode ser objeto de rigorosa verificação da ciência natural".' Isso implica a controvertida questão do estabelecimento de uma concepção científica da história. Uma tal concepção assume como conseqüência, no próprio texto marxista, a determinação do ser do homem não por sua consciência, mas por seu ser social, implicando, ao fim, a discussão, comum, ademais, a todas as filosofias da história, concernente ao problema da liberdade.

2 Cfr. HERRERO, Javier. Teoria da história em Kant. Sintese. Belo Horizonte: v. 8, n. 22, maio/ago. 1981. Pode-se dizer que, com isso, Kant faz migrar um conceito do entendimento para aquele de uma mera idéia da razão. Ou então, como ele pode transformar um juízo teleológico num juízo do entendimento sobre a natureza.

3 Cfr. KANT, I. Idéia de uma história universal com um propósito cosmopolita. In: A paz perpétua e outros opúsculos. Lisboa: E. 70, 1988. Quarta proposição, p. 25, A 392.

4 Cfr. HEGEL, G. W. F. Lecciones sobre la filosofia de la historia universal. Madrid: Alianza, 1986. p. 97.

5 Cfr. DUTRA, Delamar José Volpato. História e liberdade em Hegel e Marx. Chronos. Caxias do Sul, v. $24, \mathrm{n} .1$, jan.-jul. 1991. p. 30-44.

- MARX, Karl. Prefácio "Para a critica da economia política". In: Manuscritos econômico-filosóficos e outros textos escolhidos. 2. ed., São Paulo: Abril Cultural, 1978. p. 129-130.

7 MARX, Karl. Prefácio "Para a crítica da economia política". In: Manuscritos econômico-filosóficos e outros textos escolhidos. 2. ed., São Paulo: Abril Cultural, 1978. p. 130. 
Habermas considera que os herdeiros do marxismo pertencentes à Escola de Frankfurt, também participam das esperanças da filosofia da história. Isso é bem verdade pela constatação, desesperadà, que tal mecanismo não funciona mais. Ao menos segundo Habermas, essa posição é, marcadamente, correta até a década de 40 quando Horkheimer e Adomo publicam a Dialética do esclarecimento. ${ }^{8}$ Tomando as análises de Marcuse ${ }^{9}$ que analisam a peculiar fusão entre técnica e dominação, ${ }^{10}$ Habermas conclui: "a racionalidade da dominação mede-se pela manutenção de um sistema que pode permitir-se converter em fundamento da sua legitimidade o incremento das forças produtivas associado ao progresso técnicocientífico"." Dessa forma, "o pensamento de que as relações de produção pudessem medir-se pelo potencial das forças produtivas fica cerceado pelo fato de que as relações de produção existentes se apresentam como a forma de organização tecnicamente necessária de uma sociedade racionalizada". ${ }^{12}$ Ou seja, as forças produtivas deixam de representar um potencial de emancipação sobre as relações de produção ${ }^{13}$ e passam, ao contrário, a justificá-las. Deixa, portanto, de funcionar aquele mecanismo básico da filosofia da histónia marxista que lhe permitia atribuir um potencial de emancipação, determinado pelo inexorável aumento das forças produtivas.

Ora, é também na década de 40 que Benjamin publica Über den Begriff der Geschichte, que enterra, de vez, a filosofia da história. Tanto a crítica de Benjamin, quanto a de Habermas buscam explicitar o que se poderia chamar de problema epistemológico e mesmo ontológico da filosofia da história. Ou seja, sua abordagem consiste em afirmar que as coisas não se passam dessa forma, ou, então que não podemos fazer um juízo de conhecimento sobre determinações teleológicas. Como exemplo de uma crítica ontológica, temos a Tese IX, a alegoria do do Anjo da histónia, a qual caracteriza o passado histórico como um monte de escombros. Já a Tese XIV dá uma idéia positiva do que seja, epistemologicamente, a história, ou seja, uma construção. A nós, aqui, interessa a Tese I, que traz a alegoria do enxadrista. Ela nos dá, com precisão, os contomos epistemológicos que nos permitem asserir o conhecimento da filosofia da história. Citemo-la:

- Cfr. HABERMAS, J. Teoria de la acción comunicativa: complementos y estudios previos. Madrid: Cátedra, 1989. p. 414-415.

Cfr. MARCUSE, H. The one-dimensional man. Boston, 1964.

Cfr. HABERMAS, J. Técnica e ciência como "ideologia". Lisboa: Ed. 70, 1987. p. 50.

"HABERMAS, J. Técnica e ciência como "ideologia". Lisboa: Ed. 70, 1987. p. 47. Isso implicará, para Habermas, por outro lado, uma nova forma de conceber a ideologia, determinada pelo fato de que "o estado das forças produtivas represente precisamente também o potencial, pelo qual, medidas 'as renúncias e as incomodidades impostas aos individuos estas surgem cada vez mais como desnecessárias e irracionais'" [HABERMAS, J. Técnica e ciência como “ideologia". Lisboa: Ed. 70, 1987. p. 47]. Essa nova forma de conceber a ideologia, como tecnocracia, toma, verdadeiramente 0 sentido próprio da ideologia, ou seja, aquela que pode conceber-se ao modo da ciência, permitindose, ainda, evitar um discurso de ocultamento, lacunar [cfr. CHAUI, M. Cultura e democracia. 3. ed., São Paulo: Modema, 1982. p. 7], mas abandonando, agora, qualquer tentativa de encobrir, ideologicamente, as disfunções do sistema, as quais aparecem como tecnicamente necessárias. Para uma possivel crítica a essa nova figura da ideologia ver: DUTRA, Delamar José Volpato. A estrutura do pensamento da teodicéia de Leibniz e a vingança da ideologia contra o discurso crítico. Dissertatio, v. 2 , n. 4 , 1996. p. $97-109$.

12 HABERMAS, J. Técnica e ciência como "ideologia". Lísboa: Ed. 70, 1987. p. 48.

13 Cfr. HABERMAS, J. El discurso filosófico de la modemidad. Madrid: Taurus, 1989. p. 161. 
"como se sabe, havia uma vez um autômato, construído de modo tal que ele respondia a cada lance de um enxadrista com um outro lance que acabava lhe assegurando a vitória. Um boneco, em roupagem turca e com um cachimbo na boca, estava sentado diante do tabuleiro, colocado sobre uma mesa espaçosa. Mediante um sistema de espelhos, criava-se a ilusão de que essa mesa era transparente. Na verdade, um anão corcunda, mestre em xadrez, estava sentado dentro dela, dirigindo a mão do boneco através de cordas. Pode-se imaginar um equivalente dessa aparelhagem na filosofia. Vencer deve sempre o boneco que se chama de 'materialismo histórico'. Ele pode enfrentar a qualquer um, desde que tome a seu serviço a teologia, que, como se sabe, hoje é pequena e horrivel e que, de qualquer modo, não deve deixar-se ver." ${ }^{14}$

É assim que o materialismo histórico consegue olhar toda a história e encontrar nessa um mecanismo capaz de explicá-la em sua totalidade e de tal forma que seu ponto de vista sempre vença. De fato, afirma o próprio Marx:

"é por isso que a humanidade só se propõe as tarefas que pode resolver, pois, se se considera mais atentamente, se chegará à conclusão de que a própria tarefa só aparece onde as condições materiais de sua solução já existem, ou, pelo menos, são captadas no processo de seu devir. Em grandes traços podem ser caracterizados, como épocas progressivas da formação econômica da sociedade, os modos de produção: asiático, antigo, feudal e burguês modemo. As relações burguesas de produção constituem a última forma antagônica do processo social de produção [...] contudo, as forças produtivas que se encontram em desenvolvimento no seio da sociedade burguesa criam ao mesmo tempo as condições materiais para a solução deste antagonismo."

Assim sendo, o teorema básico da teoria da história justifica a esperança na completa emancipação da sociedade, possibilitado pelo axioma base da concepção de história de Marx. Portanto, a teoria dos modos de produção, cujo término é a sociedade comunista, emancipada, desdobra-se segundo a necessidade própria de um sistema de axiomas e teoremas. ${ }^{16}$

A tese de Benjamin nos permite compreender como é possível construir um tal juízo sobre a história. Uma tal possibilidade somente é possível pelo empréstimo do olhar de Deus sobre a história, um olhar sub specie aeternitatis. De fato, que a filosofia da história tome emprestado seu pensamento à teologia é reconhecido pelo próprio Hegel:

"os cristãos estão, pois, iniciados nos mistérios de Deus e deste modo nos há sido dada, também, a chave da história universal. No cristianismo há um conhecimento determinado da Providência e de seu plano. No cristianismo é doutrina capital que a Providência regeu e rege o mundo; que tudo quanto ocorre no mundo está determinado pelo governo divino e é conforme a este. Esta doutrina vai contra a idéia do acaso e contra a dos fins limitados: por exemplo, o da conservação do povo judeu. Há um fim último, universal, que existe em si e por si. A religião não rebaixa essa representação

${ }^{14}$ BENJAMIN, W. Teses sobre a filosofia da história. São Paulo: Ática, 1985. Tese I.

15 MARX, Karl. Prefácio "Para a crítica da economia palitica". In: Manuscritos econômico-filosóficos e outros textos escolhidos. 2. ed., São Paulo: Abril Cultural, 1978. p. 130.

16 Para Benjamin a idéia de progresso nas teorias politicas da classe trabalhadora foi mesmo prejudicial, pois, o fato de pensar estar navegando a favor da correnteza [Tese XI implica, sempre, uma grande dose de conformismo e acomodação, como se, em todo caso, as coisas não dependessem só das açōes humanas. 
geral. A religião atém-se a essa generalidade. Mas, essa fé universal, a crença de que a história universal é um produto da razão eterna e que a razão determinou as grandes revoluções da história, é o ponto de partida necessário da filosofia em geral e da filosofia da história universal. ${ }^{\text {p17 }}$

Temos, pela teologia, a chave da filosofia da história. Pode-se dizer, com Benjamin, que a filosofia da histónia só é possivel com esse olhar de Deus, para nós, em todo caso, sempre ilusório, não passando mesmo de uma fé universal. Segundo Habermas, na teologia da história dos padres da igreja estava já pensado, antecipadamente, aquilo que a filosofia da história pretende fazer uma consideração científica ${ }^{18}$ Essa consideração da história no seu todo é uma herança teológica herdada pela filosofia. ${ }^{19}$

\section{A dialética do senhor e do escravo ou o que é esquecido}

Gostariamos de apontar para o elemento que a consideração do olhar teológico supre, e que concerne a um elemento obliterado nas filosofias da histónica, um elemento que marca, digamos, o insucesso das concepções da filosofia da história, ou seja, cujo esquecimento determina a ilusão do olhar "filosófico" sobre o todo da história, constituido, na verdade, por enunciados pseudonormativos acerca de uma teleologia objetivista da história, misturando conteúdos descritivos e conteúdo normativos. ${ }^{20}$

\subsection{Hegel}

Gostaríamos de começar nossa abordagem por um elemento que parece determinante na concepção marxista da história e que se dá, com precisão, num ponto que não pode ser analisado objetivamente, a nosso ver, a saber, aquele cuja famosa parábola hegeliana do senhor e do escravo ${ }^{21}$ é sua mais clara manifestação. Ora, reconstruiremos, num primeiro momento os passos de uma tal dialética.

HEGEL, G.W.F. Lecciones sobre la filosofia de la historia universal. Madrid: Alianza, 1986. p. 55.

Cfr. HABERMAS, J. Teoria y práxis. Madrid: Tecnos, 1987. p. 258-9.

Cfr. HABERMAS, J. Teoria de la acción comunicativa: complementos y estudios previos. Madrid: Cátedra, 1989. p. 441.

${ }^{21}$ A relação dessa figura com a teoria da histónia marxista é sugerida por HYPPOLITE, Jean. Génesis y estructura de la "Fenomenologia del espiritu" de Hegel. 2. ed., Barcelona: Península, 1991. p. 156. Lima Vaz faz a mesma observação, mas adianta que o contexto especulativo no qual foi concebida tal parábola, como ele mesmo a nomeia, é "mais amplo e complexo do que aquele ao qual a reduziram a hermenêutica marxiana e as versões marxistas posteriores" (LIMA VAZ, H. C. de. Senhor e escravo: uma parábola da filosofia ocídental. Síntese. Belo Honzonte: v. 8, n. 21, jan./abr. 1981. p. 7]. De fato, nós não negamos isso, apenas queremos mostrar, através de semelhante parábola, 0 que as teses da filosofia da história, em geral, pressupõem, como operante e, ao mesmo tempo, como contra-partida, obliteram, isto é, esquecem o problema da liberdade implicado nessa consideração. Ver, também, com relação a essa temática: BORGES, M. de L. A. Os jogos da alteridade: uma análise da figura do senhor e do servo na "Fenomenologia do espirito" de Hegel. [Dissertaçāo de mestrado, UFRGS, 1990], especialmente, o Apêndice I: A utilização da figura na obra marxiana: o senhor e o servo como o trabalhador e o não-trabalhador, p. $247 \mathrm{~s}$. 
Segundo Hegel, o conceito de reconhecimento implica que "a consciência-desi é em si e para si quando e porque é em si e para si para uma Outra". ${ }^{22}$ Assim, antes do reconhecimento, na consciência-de-si "nada há nela que não seja mediante ela mesma", ${ }^{23}$ ou seja, "de início, a consciência-de-si é ser-para-si simples, igual a si mesma mediante o excluir de si todo o outro". ${ }^{24}$ Numa tal perspectiva será fatal o encontro com outra consciência, o que implicará o confronto das consciências: "mas o Outro é também uma consciência-de-si; um indivíduo se confronta com outro individuo [...] os individuos são um para outro [...] figuras independentes, consciências imersas no ser da vida" ${ }^{25}$

Para Hegel, ainda, numa tal relação da consciência consigo mesma ela não encontra verdade alguma, pois uma tal verdade só seria possivel por um outro que a reconhecesse. De fato, Hegel afirma: "sem dúvida, cada uma está certa de si mesma, mas não da outra; e assim sua própria certeza de si não tem verdade nenhuma, pois sua verdade só seria se seu próprio ser-para-si lhe fosse apresentado como objeto independente" ${ }^{26}$ porém, de acordo com o conceito do reconhecimento, isso só é possível pela pura abstração do ser-para-si. Para se chegar ao nível do que podemos chamar a verdade da consciência, a consciência de si deverá "mostrar-se como pura negação de sua maneira de ser objetiva" ${ }^{27}$ e mostrar que não está vinculada nem à vida.

Havendo duas consciências que se relacionam ao modo da certeza imediata de si mesmas, o seu agir implicará uma tendência à morte da outra, instaurandose uma luta de vida ou morte. Só assim elevam à verdade sua certeza de ser-parasi. Para que se chegue a um tal resultado, é decomposta, na experiência da luta de vida ou morte, a unidade da consciência-de-si e da vida, surgindo duas figuras: "uma, a consciência independente para a qual o ser-para-si é a essência; outra, a consciência dependente para a qual a essência é a vida, ou o ser para um Outro. Uma é o senhor, outra o escravo". ${ }^{28}$

Colocadas essas duas figuras, a nós interessará, antes de tudo, a resolução oferecida por Hegel da segunda figura, posto que "a verdade da consciência independente é por conseguinte a consciência escrava", ${ }^{29}$ pois "a escravidão, ao realizar-se cabalmente, vai tornar-se, de fato, o contrário do que é imediatamente", ou seja, se converterá em verdadeira independência.

O senhor relaciona-se, mediatamente, com o escravo pela vida, posto que o medo da morte, para Hegel, é o início da sabedoria. Por outro lado, o apego à vida torna-se a cadeia do escravo. O senhor relaciona-se, ainda, também mediata-

\footnotetext{
HEGEL, G. W. F. Fenomenologia do espíito. [2 v.]. Petrópolis: Vozes, 1992. \$178. HEGEL, G. W. F. Fenomenologia do espínto. [2 v.]. Petrópolis: Vozes, 1992. \$182. HEGEL, G. W. F. Fenomenologia do espírito. [2 v.]. Petrópolis: Vozes, 1992. \$186. HEGEL, G. W. F. Fenomenologia do espírito. [2 v.]. Petrópolis: Vozes, 1992. §186. HEGEL, G. W. F. Fenomenologia do espíito. [2 v.]. Petrópolis: Vozes, 1992. \$186. HEGEL, G. W. F. Fenomenologia do espirito. [2 v.]. Petrópolis: Vozes, 1992. §187. HEGEL, G. W. F. Fenomenologia do espirito. [2 v.]. Petrópolis: Vozes, 1992. §189. HEGEL, G. W. F. Fenomenologia do espírito. [2 v.]. Petrópolis: Vozes, 1992. \$193. HEGEL, G. W. F. Fenomenologia do espínto. [2 v.]. Petrópolis: Vozes, 1992. \$193.
} 
mente, com a coisa por meio do escravo. ${ }^{31}$ Ora, a consciência escrava pode ser caracterizada, então, pelo medo da morte, que como afirma Hegel é, tão somente, o início da sabedoria, já que, aí, não se encontra a si mesma, o que acontecerá, finalmente, pelo segundo elemento que caracteriza a consciência escrava, a saber, o trabalho. ${ }^{32}$

O trabalho é desejo refreado, posto que não pode consumir a coisa para realizar o gọzo na negação completa da coisa. Ou seja, o trabalho forma, para Hegel. No trabalho, a consciência depara-se com o independente que funcionará como contemplação de si mesma, ou seja, o puro ser da consciência, no trabalho, transfere-se para fora de si no elemento do permancer: "a consciência trabalhadora, portanto, chega assim à intuição do ser independente, como [intuição] de si mesma" ${ }^{33} \mathrm{O}$ medo e o trabalho são necessários para que haja tal reflexão. Mas, "é o trabalho que transforma a escravidão em senhorio [...] formando as coisas, o escravo não só se forma a si mesmo, mas também imprime ao ser esta forma que é a da autoconsciência e, com isso, encontra-se a si mesmo em sua obra". ${ }^{34} \mathrm{O}$ trabalho possui, ademais, um significado negativo, libertando do medo, na medida em que "no formar, o ser-para-si se torna para ele como o seu próprio, e assim chega à consciência de ser ele mesmo em si e para $\mathrm{si}^{\prime \prime}{ }^{35}$ ou seja, nesse reencontra-se de si por si mesma, a consciência vem a ser em sentido próprio. ${ }^{36}$

\subsection{A Escola de Frankfurt}

O ponto a destacar, para os fins de nossa análise, consiste no momento preciso em que a consciência nesse trabalho que forma, chega a deparar-se com a independência da coisa e a reconhecer sua própria independência no trabalho que forma, acontecendo, por conseqüência, também, a libertação do medo. Se nossa tese estiver correta, é necessánio pressupor que essa dialética, ou reflexão, ao nível da consciência, da subjetividade, de fato aconteça. Se ela acontece, então, a leitura da história como um processo de emancipação necessariamente ocorre, pois nós podemos, dessa forma, conciliar as ações humanas com a necessidade de que perfaçam um caminho muito além do que elas próprias põem como sua finalidade. Ou seja, se o processo de emancipação, na filosofia da história marxista, presumia a ação revolucionária e emancipatória de uma classe, nós podemos, a partir da figura do senhor e do escravo, encontrar uma base que nos autorize a estatuí-la como classe revolucionária. Algo que acontecerá, inelutavelmente, no processo de trabalho, onde a consciência chegaria à intuição, ou à reflexão de que

31 Cfr. HEGEL, G. W. F. Fenomenologia do espirito. [2 v.]. Petrópolis: Vozes, 1992. \$190. Cfr., em acréscimo, o comentário de Hyppolite: HYPPOLITE, Jean. Génesis y estructura de la "Fenomenologia del espiritu" de Hegel. 2. ed., Barcelona: Península, 1991. p. 157.

32

HEGEL, G. W. F. Fenomenologia do espinito. [2 v.]. Petrópolis: Vozes, 1992. §195. "A verdade dessa intuição de si no ser em si é, justamente, o pensamento estóico que a manifestará" [HYPPOLITE, Jean. Génesis y estructura de la "Fenomenologia del espiritu" de Hegel. 2. ed., Barcelona: Peninsula, 1991. p. 160]. HYPPOLITE, Jean. Génesis y estructura de la "Fenomenologia del espíritu" de Hegel. 2. ed., Barcelona: Península, 1991. p. 159-60. 
ela é sujeito da história, implicando o senhorio do mundo por ela e a perda do medo. Ou seja, a resolução, bem sucedida, da figura implicará, no jargão marxista, que o proletariado poderá instituir-se como a classe da qual, na verdade, depende a classe burguesa. Isso seria condição de possibilidade, enquanto consciência, tanto de uma greve, quanto de uma revolução.

Pois bem, se presumirmos que ações humanas devem ser sempre tomadas como as fundamentais no processo histórico, então, ao nível de sua própria formação, para que as teses da filosofia da história funcionem, nós devemos asserir-lhe algum grau de necessidade, necessidade essa, em todo caso, que a filosofia da história pressuponha no processo de emancipação. E só tendo isso como pressuposto é que Marx pode escrever que o aumento das forças produtivas implica uma força emancipatória sobre as relações de produção e que a história seria a história da luta de classes.

Porém, o que os frankfurtianos constatarão, enfim, será a imobilização da figura do senhor e do servo. Ou seja, o sistema desenvolveu, em sua perspectiva, mecanismos que impedem a reflexão ou a intuição da consciência escrava, ou da consciência que no trabalho forma mundo. Uma tal perspectiva pode ser tomada plausivel a partir de uma radicalização da figura da ideologia, cuja relevância e poder não podem ser subestimados. A nosso ver, o papel da ideologia é dado pelo tratamento do tema da indústria cultural para além de suas implicações estéticas, considerando, portanto, as implicações de caráter político, antropológico e, no caso, propriamente filosófico, isso na medida em que averigua as ressonâncias desse conceito sobre a dialética da consciência.

A Dialética do esclarecimento é uma manifestação clara de uma tal visão da figura do senhor e do servo, ou seja, a descrição da imobilização de uma tal dialética. Vejamos como Adomo e Horkheimer tratam aí a questão. Essa apresentação é feita com uma alusão ao canto da sereias da Odisséia de Homero. A obra começa pela definição do esclarecimento: "no sentido mais amplo do progresso do pensamento, o esclarecimento tem perseguido sempre o objetivo de livrar os homens do medo e de investi-los na posição de senhores". ${ }^{37}$ Ora, o desejo de Ulisses de conhecer o canto das sereias e de não submergir ao seus encantos é tomado como ilustrativo do processo do esclarecimento. Na narrativa estão presentes o que interessa a Adorno e Horkheimer analisar, ou seja, o conhecimento, o medo da morte, a identidade do eu, e, principalmente, o trabalho. "O medo de perder 0 eu e o de suprimir com o eu o limite entre si mesmo e a outra vida, o temor da morte e da destruição, está irmanado a um a promessa de felicidade, que ameaçava a cada instante a civilização. $O$ caminho da civilização era o da obediência e do trabalho, sobre o qual a satisfação não brilha senão como mera aparência". ${ }^{39} 0$ preço que Ulisses paga, para poder conhecer e dominar o canto das sereias, sem sucumbir a ele, é damasiadamente pesado, pois, nesse processo, o trabalho necessário para que tal aconteça é de tal forma inibidor das capacidades reflexivas dos seus servos que acabará por atingir a sua própria emancipação, posto que

37 ADORNO, Th. W., HORKHEIMER, Max. Dialética do esclarecimento: fragmentos filosóficos. Rio de Janeiro: Zahar, 1985. p. 19.

38 ADORNO, Th. W., HORKHEIMER, Max. Dialética do esclarecimento: fragmentos filosóficos. Rio de Janeiro: Zahar, 1985. p. 44-5. 
dependente da consciência destes. De fato, aos seus companheiros "ele tapa seus ouvidos com cera e obriga-os a remar com todas as forças de seus músculos [...] ele escuta, mas amarrado impotente ao mastro". ${ }^{\circ}$

É, bem entendido, nesse contexto, que eles citam a Hegel: "mas o senhor introduziu o escravo entre ele e a coisa, e assim se conclui somente com a dependência da coisa, e puramente goza; enquanto o lado da independência deixa-o ao escravo, que a trabalha". ${ }^{40}$ De fato, Ulisses é substituído no trabalho e os servos "não podem desfrutar do trabalho porque este se efetua sob coação, desesperadamente, com os sentidos fechados à força. O servo permanece subjugado no corpo e na alma, o senhor regride [...] a fantasia atrofia-se". ${ }^{41}$ Pode-se perceber, claramente, a intenção dos autores na citação de uma passagem da clássica figura do senhor e do escravo da Fenomenologia. A sua intenção é clara ao assinalar a dominação do corpo e da alma, implicando a atrofia da fantasia. Além disso, a regressão "afeta ao mesmo tempo o intelecto autocrático". ${ }^{42}$ Finalmente, concluindo a sua análise, os autores negam a afirmativa hegeliana de que a verdade da consciência independente seja a consciência escrava: "os ouvidos moucos, que é o que sobrou aos dóceis proletários desde os tempos míticos, não superam em nada a imobilidade do senhor". ${ }^{43}$ Afirmativa derradeira para a figura do escravo, equiparada, agora, à não verdade da consciência do senhor. Assim, o conformismo é a consequiência lógica da sociedade industrial, onde, finalmente, "o pensamento perdeu o elemento da reflexão sobre si mesmo, e hoje a maquinaria mutila os homens mesmo quando os alimenta" ${ }^{4}$ A Dialética do esclarecimento lê a histónia de uma forma contrária ao implícito na parábola hegeliana, ou seja, "a história da civilização é a história da introversão do sacrifício. Ou por outra, a história da renúncia". ${ }^{45}$ Trata-se, no dizer da obra, da "transformação do sacrifício em subjetividade" ${ }^{46}$ A indústria cultural tem, nessa análise, como conseqüência, a atrofia da imaginação e da espontaneidade. ${ }^{47}$ Ela reprime, não sublima, ${ }^{48}$ no jargão

39 ADORNO, Th. W., HORKHEIMER, Max. Dialética do esclarecimento: fragmentos filosóficos. Rio de Janeiro: Zahar, 1985. p. 44-5.

40 HEGEL, G.W.F. Fenomenologia do espirito. [2 v.]. Petrópolis: Vozes, 1992. \$190.

41 ADORNO, Th. W., HORKHEIMER, Max. Dialética do esclarecimento: fragmentos filosóficos. Rio de Janeiro: Zahar, 1985. p. 46.

4 ADORNO, Th. W., HORKHEIMER, Max. Dialética do esclarecimento: fragmentos filosóficos. Rio de Janeiro: Zahar, 1985. p. 46-7.

43 ADORNO, Th. W., HORKHEIMER, Max. Dialética do esclarecimento: fragmentos filosóficos. Rio de Janeiro: Zahar, 1985. p. 47.

4 ADORNO, Th. W., HORKHEIMER, Max. Dialética do esclarecimento: fragmentos filosóficos. Rio de Janeiro: Zahar, 1985. p. 48.

45 ADORNO, Th. W., HORKHEIMER, Max. Dialética do esclarecimento: fragmentos filosóficos. Rio de Janeiro: Zahar, 1985. p. 61. "Graças à resignação com que se confessa como dominação e se retrata na natureza, o espirito perde a pretensão senhorial que justamente o escraviza à natureza" [ADORNO, Th. W., HORKHEIMER, Max. Dialética do esclarecimento: fragmentos filosóficos. Rio de Janeiro: Zahar, 1985. p. 50].

46 ADORNO, Th. W., HORKHEIMER, Max. Dialética do esclarecimento: fragmentos filosóficos. Rio de Janeiro: Zahar, 1985. p. 61. Eles falam, a partir de Tocqueville, de um apodrecer espiritual: "segundo Tocqueville, as repúblicas burguesas, ao contránio das monarquias, não violentam o corpo, mas văo direto à alma" [ADORNO, Th. W., HORKHEIMER, Max. Dialética do esclarecimento: fragmentos filosóficos. Rio de Janeiro: Zahar, 1985. p. 212].

47 Cfr. ADORNO, Th. W., HORKHEIMER, Max. Dialética do esclarecimento: fragmentos filosóficos. Rio de Janeiro: Zahar, 1985. p. 119. 
psicanalítico. O capitalismo, segundo os frankfurtianos, engendrou "mecanismos" que paralisam a dialética do senhor e do escravo, tais como, a indústria cultural e os meios de comunicação, conforto e bem-estar ${ }^{49}$ e, finalmente, a ideologia do melhor dos mundos. ${ }^{50}$

Ora, esse é o elemento base, a nosso ver, que determinará a tese central de Habermas em sua obra e, especialmente em Técnica e ciência; aliás, trata-se, apenas, da retomada de uma constatação base de toda a Escola de Frankfurt, ou seja, a imobilização da tese básica da filosofia da história marxista. Por outro lado, Habermas, fugindo a um certo pessimismo da Escola de Frankfurt, presente nos escritos tórridos de Adomo, buscará, explicitamente, calcar a sua posição, a nosso ver, exatamente naquele elemento obliterado na filosofia da história. Ora, é pela recuperação do domínio da intersubjetividade e, portanto, da liberdade, que determinará a posição habermasiana como sendo, fundalmentalmente, ética. Isso implica o ter que abandonar as teses da filosofia da história, remetendo o desafio da emancipação para o domínio da ação humana, seja ele político, jurídico ou mesmo propriamente moral, mas, sempre, em todo caso, marcado por um elemento de contingência.

\section{Referências bibliográficas}

ADORNO, Th. Dialectica negativa. (Trad. J. M. Ripalda: Negative Dialektik). Madrid: Taurus, 1975.

- Minima moralia. (Trad. L.E. Bicca: Minima Moralia). São Paulo: Ática, 1992.

- HORKHEIMER, Max. Dialética do esclarecimento: fragmentos filosóficos. [Trad. G.A. de Almeida: Dialektiik der Aufklärung: Philosophische Fragmente]. Rio de Janeiro: Zahar, 1985.

BENJAMIN, W. Teses sobre a filosofia da histónia. [Über den Begriff der Geschichte] São Paulo: Ática, 1985.

BORGES, M. de L. A. Os jogos da alteridade: uma análise da figura do senhor e do servo na "Fenomenologia do espinito" de Hegel. [Dissertação de mestrado, UFRGS, 1190].

CATORIADIS, C. L'instituition imaginaire de la société. Paris, 1975.

CHAUf, M. Cultura e democracia. 3. ed., São Paulo: Modema, 1982.

DUTRA, D. J. V. A estrutura do pensamento da teodicéia de Leibniz e a vingança da ideologia contra o discurso crítico. Dissertatio. Pelotas: v. 2, n. 4, 1996. p. 97-109.

- A fundamentação da "Teoria Critica" em Habermas. Caderno Cultural, Pelotas, ano 1, n. 0, maio 1992.

- Histónia e liberdade em Hegel e Marx. Chronos, Caxias do Sul, v. 24, n. 1, jan./jun. 1991. p. $30-44$.

- História e liberdade em Hegel e Marx. Chronos, Caxias do Sul, v. 24, n. 1, jan.-jul. 1991. p. 30-44.

ENGELS, F. A "Contribuiçâo à crítica da economia política" de Karl Marx. In: MARX, Karl, ENGELS, F. Obras escolhidas. [v. 1]. São Paulo: Alfa-Ómega, s.d. p. 304-312.

HABERMAS, J. Técnica e ciência enquanto "ideologia”. In: BENJAMIN, W. et al. Textos escolhidos. 2. ed. São Paulo: Abril Cultural, 1983. (Os Pensadores).

— El discurso filosófico de la modernidad. (Trad. M. J. Redondo: Der Philosophische Diskurs der Modeme). Madrid: Taurus, 1989.

- Habermas: sociologia. [Coleção grandes cientistas sociais, org. e trad. S. P. Rouanet e B. Freitagl. São Paulo: Ática, 1980.

48 Cfr. ADORNO, Th. W., HORKHEIMER, Max. Dialética do esclarecimento: fragmentos filosóficos. Rio de Janeiro: Zahar, 1985. p. 131.

49 Para um tratamento do papel do conforto e do bem-estar no sistema social atual, enquanto ideologia, ver: HABERMAS, J. Técnica e ciência como "ideologia". Lisboa: Ed. 70, 1987.

50 Cfr. DUTRA, Delamar José Volpato. A estrutura do pensamento da teodicéia de Leibniz e a vingança da ideologia contra o discurso critico. Dissertatio. v. 2, n. 4, 1996. p. 97-109. 
- Para a reconstrução do materialismo histórico. (Trad. C. N. Coutinho: Zur Rekonstruktion des histonischen Materialismus). 2. ed., São Paulo: Brasiliense, 1983.

- Profiles philosophiques et politiques. (Trad. F. Datur, J.-R. Ladmiral, M. B. de Launay: Philosophisch-politische Profile). Paris: Gallimard, 1974.

— . Técnica e ciência como "ideologia". (Trad. A. Morão: Techinik und Wissenschaft als "Ideologie"). Lisboa: Ed. 70, 1987.

- Teoria de la acción comunicativa (2 v.). (Trad. M. J. Redondo: Theorie des kommunicativen Handelns). Madrid: Taurus, 1987/1989.

- Teoria de la acción comunicativa: complementos y estudios previos. (Trad. M.J. Redondo: Vorstudien und Ergänzungen zur Theorie des Kommunikativen Handelns). Madrid: Cátedra, 1989.

—. Teoria y práxis, Madrid: Tecnos, 1987.

- Theorie des kommunicativen Handelns. (2 v.). Frankfurt am Main: Suhrkamp, 1981.

- Vorstudien und Ergänzungen zur Theorie des Kommunikativen Handelns. Frankfurt am Main: Suhrkamp, 1984.

HEGEL, G.W.F. Fenomenologia do espírito. [2 v., trad. P. Menezes e H.-H. Efken: Phänomenologie des Geistes]. Petrópolis: Vozes, 1992.

—_. Lecciones sobre la filosofia de la historia universal. [Trad. José Gaos: Vorlesungen über die philosophie der Geschichte]. Madrid: Alianza, 1986.

HERRERO, Javier. Teoria da história em Kant. Sintese, Belo Horizonte, v. 8, n. 22, maio/ago. 1981.

HORKHEIMER, M., ADORNO, Th. Dialética do esclarecimento: fragmentos filosóficos. [Trad. G.A. de

Almeida: Dialektik der Aufklänung: Philosophische Fragmente]. Rio de Janeiro: Zahar, 1985.

HYPPOLITE, Jean. Génesis y estructura de la "Fenomenologia del espiritu" de Hegel. [Trad. F.F. Buey:

Genèse et structure de la "Phénoménologie de l'esprit" de Hegel]. 2. ed., Barcelona: Península, 1991.

KANT, I. A paz perpétua e outros opúsculos. (Trad. A. Morão). Lisboa: E. 70, 1988.

- Idéia de uma história universal de um ponto de vista cosmopolita. [Trad.: Ricardo R. Terra e Rodrigo Naves]. São Paulo: Brasiliense, 1986.

LEIBNIZ, G. W. A Monadologia. IN: NEWTON, I. \& LEIBNIZ, G. W. Textos Escolhidos. São Paulo: Abril Cultural, 1979. (Os Pensadores).

- Discurso de metafísica. IN: NEWTON, I. \& LEIBNIZ, G. W. Textos Escolhidos. São Paulo: Abril Cultural, 1979. (Os pensadores).

- Essais de théodicée sur la bonté de Dieu, la liberté de l'homme et l'origine du mal. [2 v., bilíngüe]. 2. ed., Frankfurt am Main: Insel, 1986.

LIMA VAZ, H. C. de. Senhor e escravo: uma parábola da filosofia ocidental. Sintese, Belo Horizonte, v. 8, n. 21, jan./abr., 1981. p. 7-29.

LIMA, C. R. V. C. Sobre a contradição performativa como fundamentação do sistema. Sintese, Belo Horizonte, v. 18 , n. 55,1991 . p. 595-616.

MARCUSE, $\mathrm{H}$. The one-dimensional man. Boston, 1964.

MARX, Karl. O manifesto comunista. Rio de Janeiro: Zahar, 1982.

- Introduccion para la critica de la 'Filosofia del derecho' de Hegel. (Trad. A. M. de Montero: Zur Kritik der Hegel schen Rechts - Philosophie]. In: HEGEL, G. W. F. Filosofia del derecho. 5. ed. Buenos Aires: Claridad, 1968. p. 7-22.

- Manuscritos econômico-filosóficos e outros textos escolhidos. 2. ed., São Paulo: Abril Cultural, 1978.

—. Prefácio à "Contribuição à crítica da economia política". In: MARX, Karl, ENGELS, F. Obras escolhidas. [v. 1]. São Paulo: Alfa-Ómega, s.d. p. 300-303.

POPPER, Karl. A miséria do historicismo. [L. Hegenberg e O.S. da Mota: The poverty of historicism].

São Paulo: Cultrix/EDUSP, 1980.

STEIN, E. Crítica da idelogia e racionalidade. Porto Alegre: Movimento, 1986.

TUGENDHAT, E. Self-consciousness and self-determination. [Paul Stem: Selbstbewustsein und

Selbstbestimmung. Sprachanalytische Interpretationen]. Massachusetts: The MIT Press, 1986.

WEBER, Th. Hegel: liberdade, estado e história. Veritas, Porto Alegre, v. 38, n. 149, mar. 1993. p. 5-16.

ZINGANO, M. A. Razão e histónia em Kant. São Paulo: Brasiliense/CNPq, 1989. 